\title{
EPIDEMIC ENCEPHALITIS
}

\section{CLINICAL AND PATHOLOGIC STUDY OF TWENTY-FIVE CASES}

\author{
MORRIS E. ALEXANDER, M.D. \\ Visiting Physician, Waterbury Hospital \\ WATERBURY, CONN.
}

INTRODUCTORY

In a previous communication, H. E. Allen and $\mathrm{I}^{1}$ reported four cases of lethargic encephalitis as seen in the early part of the epidemic, and reviewed the literature and cases reported up to that time. After a short interval, during which few cases were seen in our community, a sudden recrudescence occurred. During this recrudescence I had the opportunity to study twenty-five cases of the disease and also to make necropsy examinations of several. These cases I shall report.

\section{GENERAL CONSIDERATIONS}

Age and Sex.-The youngest patient was 16 years of age; the oldest 61 . Nineteen of the twenty-five were between 25 and 40 years old. Eighteen were males and seven females.

Relation to Influenza.-Direct: Of the twenty-five patients. observed, only two gave a history of influenza. It consisted of a mild attack six weeks and four months, respectively, prior to the encephalitis.

Indirect: A definite relation between epidemic influenza and epidemic encephalitis was observed. The great epidemic of influenza raged during the months of October and November, 1918. We recognized the first case of epidemic encephalitis in February, 1919. Between February and October, 1919, we saw four typical cases, but from that time to February, 1920, hardly any cases were seen in the community.

A recrudescence of the influenza epidemic occurred in January, 1920, and lasted until Feb. 20, 1920, when cases of encephalitis began to appear. They gradually increased in number and reached their height in the latter part of March, when most of the cases were seen. On one day-March 24-five patients with encephalitis were admitted to the Waterbury Hospital.

Mode of Onset and Symptoms.-Premonitory symptoms of lassitude and general malaise of several days' duration were complained of by

1. Alexander, M. E., and Allen, H. E.: Lethargic Encephalitis, Arch. Neurol. \& Psychiat. 3:485 (May) 1920. 
ten of the patients. The most frequent mode of onset (sixteen cases) was with neuritic pain. In the majority of instances it commenced rather abruptly. Jerking and twitching were frequent symptoms and were among the first complained of in eighteen of the cases. In five cases the early symptoms were suggestive of a mild meningitis: rigidity of the neck, headache, tâche cerebrale and a positive Kernig's sign.

Fever: A temperature above $100 \mathrm{~F}$. was found at one time or another in all cases observed. In eighteen cases it was $102 \mathrm{~F}$. or above. It was highest in the cases associated with a great deal of twitching and neuritic pain and in those that showed signs of cortical involvement. With exacerbations the temperature generally rose

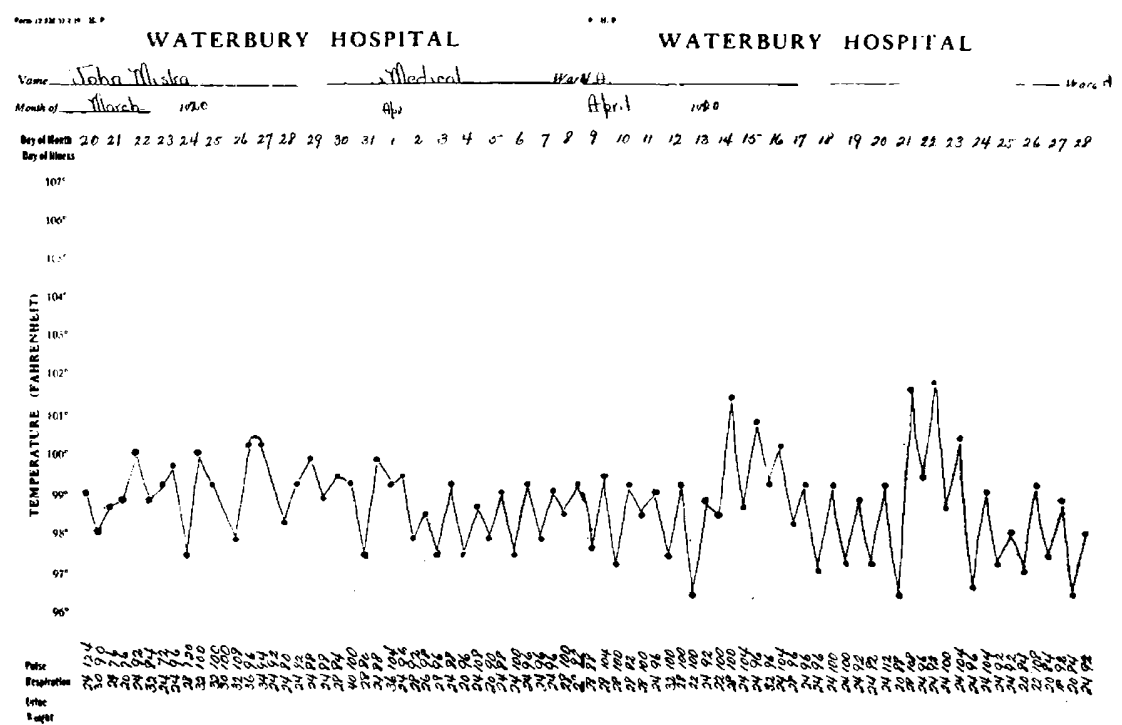

Fig. 1 (Case 10).-Usual temperature elevation in the meningoradicular type of encephalitis and the elevations with recrudescences of the disease.

(Fig. 1). In two cases hyperpyrexia was noted (Fig. 2). Both terminated fatally. The rise of temperature was irregu'ar and unless taken at frequent intervals might have been overlooked in some cases.

PULSE: The pulse presented the usual features of infectious diseases. It averaged between 90 and 100 and was generally a little faster than one would expect with the comparatively slight elevations of temperature. In patients showing evidence of marked disturbance of the basal nuclei (dysphagia and marked lethargy), the pulse was generally between 100 and 110 . A rate above 120 was uncommon, and when it persisted was of serious import. Extrasystole (transient) was noted in two cases; other irregularities of the pulse were absent. 
Blood Pressure: This was generally slightly elevated, not only during the stage of excitement but even during pronounced lethargy. In one case peculiar, temporary elevations of blood pressure were observed. On admission to the hospital it was: systolic 120; diastolic, 70. On the second day it was systolic, 190; diastolic, 100. Similar fluctuations were noted on two other occasions.

F $225 \mathrm{SM} 11310$ H.P.

\section{WATERBURY HOSPITAL}

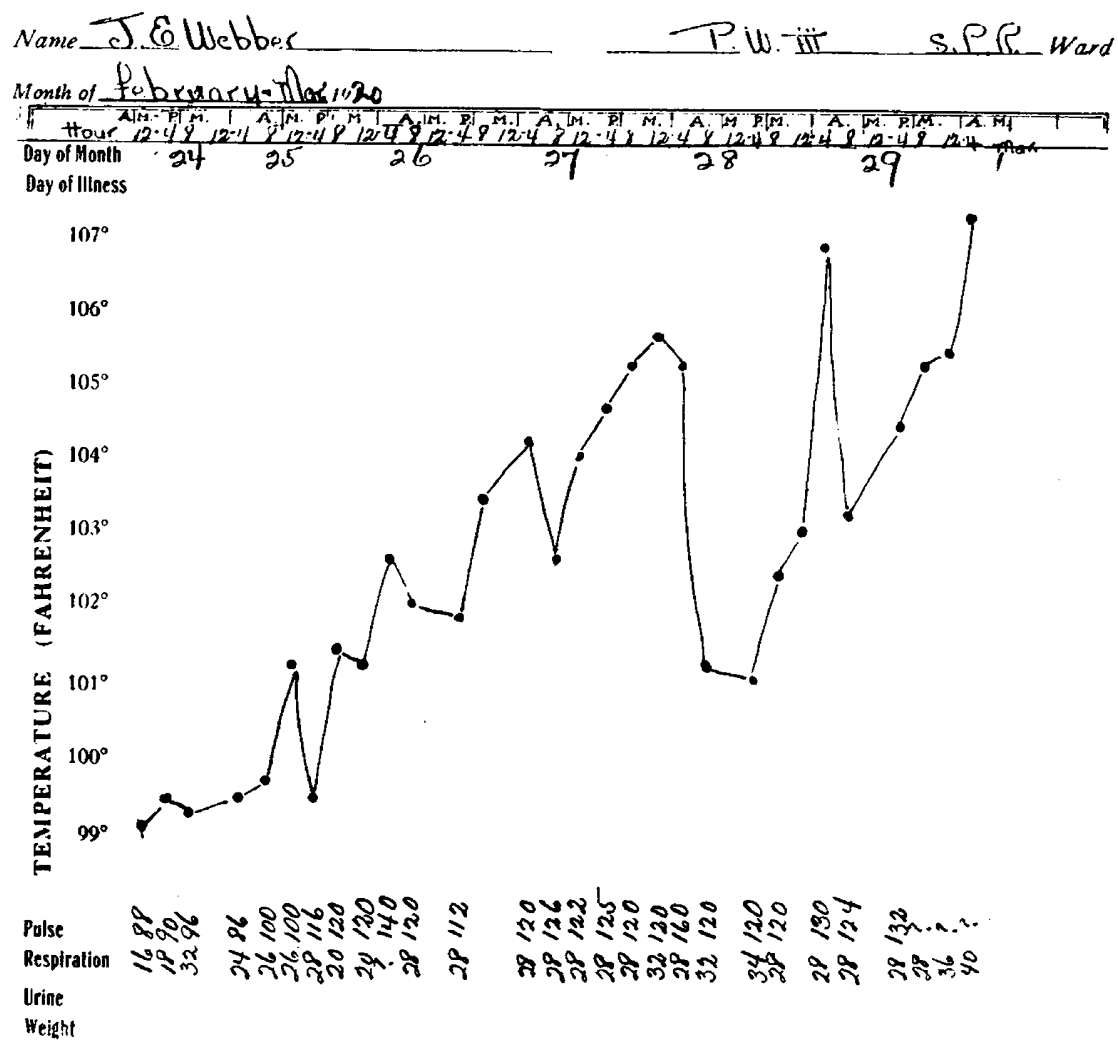

Fig. 2 (Case 16).-Temperature elevation showing hyperpyrexia. Necropsy examination revealed no complications and no pathologic findings except at the base of the brain.

\section{CENTRAL NERVOUS SYSTEM}

Restlessness and wakefulness were present in eighteen patients. In five, lethargy set in after a preliminary period of restlessness and insomnia lasting two or three weeks. These cases particularly emphasized the fact that the various cases which at certain times showed symptoms so vastly different, really belonged to the same affection. 
In most of the cases the lethargy, listlessness and masklike face were not present until the third or fourth week. Several cases, commencing with choreiform twitchings, involving at different times almost all muscles in the body, including the abdominal twitching so characteristic of this group, gradually developed into the lethargic type, with ptosis of one or both lids, diplopia and facial palsies. The patients remained in a state of lethargy and somnolence for several weeks and then, with gradual awakening of the sensorium, the various twitchings reappeared. In two cases the process was repeated three times.

Cranial Nerves.-Involvement of the cranial nerves was not so common in this series as in the earlier epidemic.

First Cranial Nerve: In the first ten cases the olfactory nerve was not examined. After noting small hemorrhages and perivascular infiltration in this nerve in one of the cases examined postmortem. the

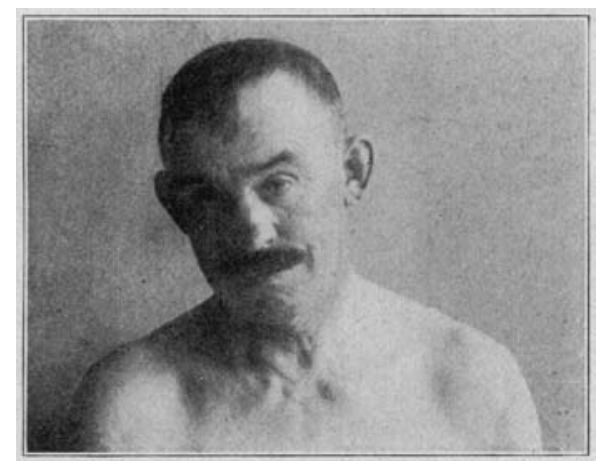

Fig. 3 (Case 8).-Spasm of sternemastoid muscle with torticollis.

sense of smell was tested in all patients. It was found markedly diminished in four cases, absent in none.

Second Cranial Nerve: No disturbances of the optic nerve were noted except in two cases. In these the diameter of the papilla seemed enlarged, the veins moderately engorged and tortuous. Around the papilla the retina was slightly opaque and striated. One of these patients died, and microscopic examination showed evidence of optic neuritis. The other patient recovered and six months after the illness all signs of choked disk had disappeared.

Third Cranial Nerve: This nerve was involved in ten cases; diplopia in four; ptosis in six; strabismus in seven. In many the various paralyses were present at different times, but they were not common at the beginning.

Fourth Cranial Nerve: Paralysis was present in three cases.

Fifth Cranial Nerve: Difficulty in mastication was present in two cases, and the masseter muscles did not seem to contract. Neither 
patient was lethargic, nor was there pronounced general weakness. In one of these there was hyperalgesia on one side of the face and an abundant crop of herpes along the upper lip. In the other there was diminution of sensibility of the lips and tongue. This patient also had excessive salivation. After six days the anesthesia gradually disappeared.

Sixth Cranial Nerve: Conjugate deviation of the paralytic form was present in four cases.

Involvement of the third, fourth and sixth nerves, as evidenced by total ophthalmoplegia, was present for a short time in two cases.

Seventh Cranial Nerve: Incomplete facial palsy was present in nine cases; in one the paralysis was bilateral.

Eighth Cranial Nerve: Diminution of the acuity of hearing was noted in six cases. Four patients complained of distressing and persistent noises in both ears.

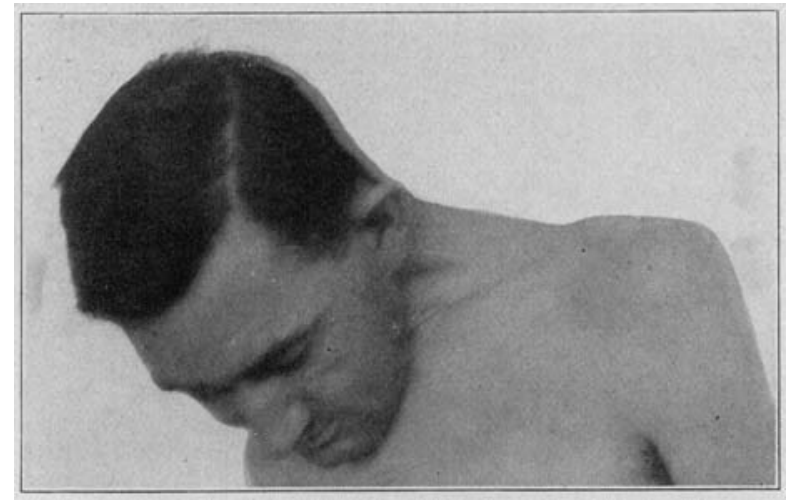

Fig. 4 (Case 11).--Spasm of sternomasto:d with torticollis; also paralysis of the muscles of the back of the neck.

Ninth Cranial Nerve: Dysphagia was present in eleven cases, lasting from three days to four weeks. In all cases it was associated with involvement of other cranial nerves, and it was difficult to determine how much the vagus or hypoglossal involvement contributed to the symptom.

Tenth Cranial Nerve: Unilateral flaccid paralysis of the soft palate was noted in two cases. Speech was nasal and deglutition difficult. There was also paralysis of the vocal cord on the same side. Marked gastric irritability and vomiting without apparent cause were present in two cases. Bulimia was present in one case, accompanied by paralysis of the vocal cords and cardiac arrhythmia-extra systole. The bulimia lasted about ten days and gradually disappeared. Irregular respiration was present in one case. It resembled very much the pulse rhythm of a sinus arrhythmia, being mainly trigeminal in character. 
Eleventh Cranial Nerve: Persistent spasm of the sternomastoid muscle was seen in one case (Fig. 1). There was paralysis of the trapezius in the same patient and to a still more marked degree in another patient (Fig. 4).

Twelfth Cranial Nerve: Unilateral paralysis of the tongue was noted in one case. Movement of the tongue within the mouth was imperfect on the right side, more so in the attempt to protrude the tongue.

\section{PERIPHERAL NERVES}

Pain.-It was the first symptom complained of in sixteen of the cases, most frequently in the face and one side of the neck, next in the extremities. The majority of the patients complained of tenseness and discomfort in the extremities and along the course of various nerves. but at times of sharp and lancinating pains. In one case it was localized in the spine and darted alternately to the right and left. In three patients the lancinating pains were very distressing, frequently sudden and flashing in character and accompanied by mild sensations of contraction. In one patient these pains persisted for four days, requiring morphia to allay them.

Sensory Disturbances.-No dissociation of sensations was observed in eleven of the cases examined for it. Hyperalgesia was noted in three cases. In one it was associated with trophic disturbancss, such as blebs and bed sores. No thermo-anesthesia was found.

Trophic and Vasomotor Disturbances.-Persistently cold, clammy and cyanotic finger tips were observed in four patients, profuse sweating in three, excessive salivation in two, decubitus in three.

Tremor.-Coarse tremor was present at some period or other in twenty cases. Its initial location and progress were ascertained in fifteen cases. In six patients it began in one extremity, nearly always a hand, and spread to the lower extremity of the same side; in three it commenced in one side of the face; in two in the abdominal muscles, in one in the muscles of the neck and shoulder, while in the rest it was practically simultaneous in nearly every part of the body.

Slight at first, it became more marked later, so that the affected part would move sufficiently to disarrange the bed clothes. The rate varied. In one patient it was $80 \mathrm{a}$ minute; in others it varied from 20 to 30 a minute. Generally disappearing during sleep, in three cases it persisted, although to a lesser degree. The patient was generally able to diminish or even to suppress it entirely for a few seconds or minutes, when it became entirely uncontrollable. Finer motions and manipulations were not affected very much: and the patients were generally able to feed themselves and write short notes, except during 
the height of the disease when the jerkings were extremely violent. Kymographic tracings revealed contractions at irregular intervals but generally of about the same amplitude.

Among the more peculiar and extraordinary spasms were those of the abdominal muscles. The upper part of the recti abdominis and external oblique muscles would contract and twitch, varying from 20 to 50 times a minute. At first the spasm resembled the movements of hiccup but observation showed that it had no relation with respiration or with contractions of the diaphragm. It was generally accompanied

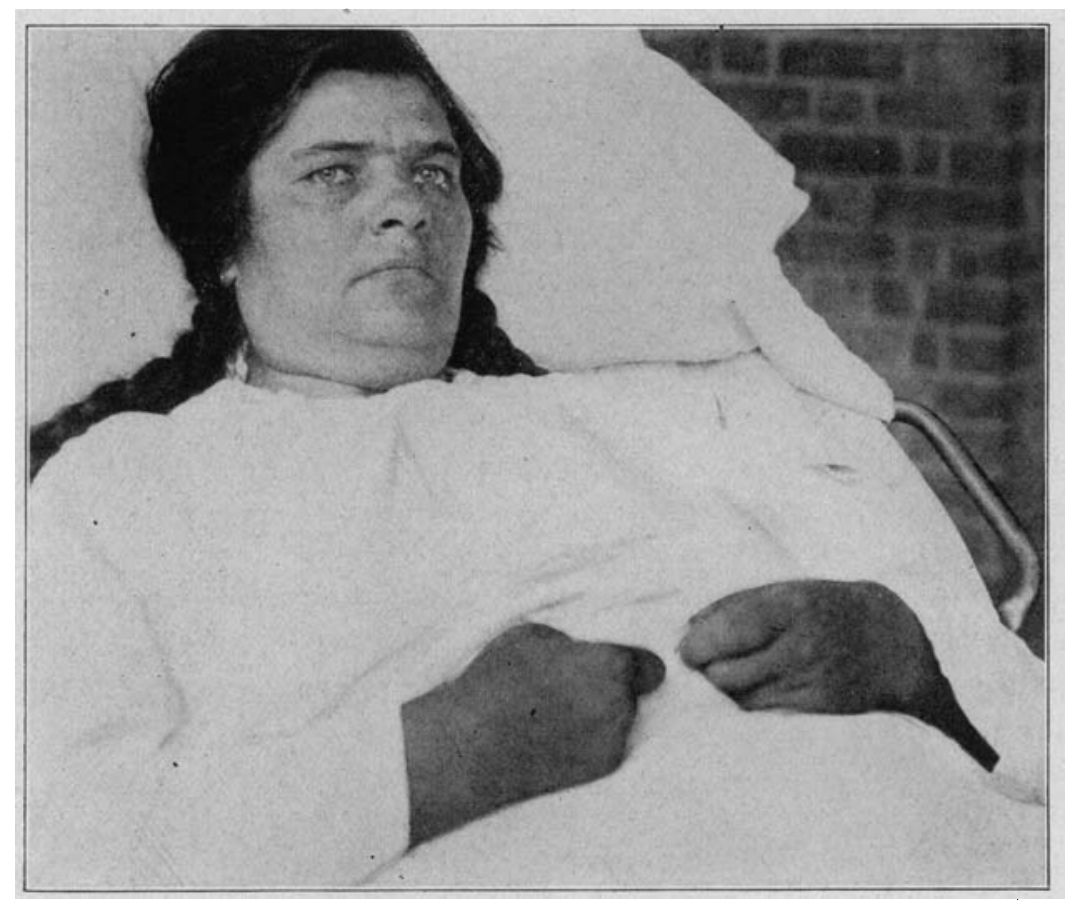

Fig. 5 (Case 15).-Choreiform type of encephalitis. A characteristic position of the hands; it resembles the driving position so frequently found in tetany.

by simultaneous spasm of the extremities and in some instances of nearly the entire voluntary body musculature.

Another extraordinary spasm, in one case, was a spasmodic, spontaneous, dorsal flexion of the right big toe with simultaneous p'antar flexion of the small toes. Occasionally fanlike separation of the small toes was seen. I could find no mention in the literature of a similar phenomenon. Tilney and Howe ${ }^{2}$ report contractions of the muscles of the big toe, but do not mention any resemblance to the Babinski

2. Tilney, F., and Howe, H. S.: Epidemic Encephalitis, New York, 1920, p. 16 . 
phenomenon. In my patient the spasm was startlingly regular in frequency, numbering from 53 to 55 a minute. Like the other spasms in the same patient, it persisted during sleep, although to a less degree. This patient recovered. The plantar flexion of the toes ceased first, dorsal flexion of the large toe persisting for some time.

In a few of our patients the position of the hands was extremely interesting. In three they made the "pill rolling" movement so characteristic of paralysis agitans. Two other cases presented the attitude found in tettany (Fig. 5). The arms were held quite close to the chest, the forearms partly flexed, and the wrist flexed, while the fingers were tightly closed over the inverted thumb, simulating the driving position. The position was maintained for many days, and in one patient was present five months after discharge from the hospital. The tonicity of the contracted fingers was evident, but it could be overcome by gentle attempts. One or two of the fingers were generally involved in a continuously intermittent spasm, although the most pronounced spasm was at the wrist. The Trousseau and the Chvostek signs were absent in both cases and neither thyroid, parathyroid therapy, nor administration of calcium affected this tetany-like phenomenon.

Muscles.-Wasting was not a prominent feature but was present to a marked degree in two cases showing evidence of nerve root and cord involvement. The bones of the shoulders, particularly the scapulae, were prominent. There was marked atrophy of the muscles of the back of the neck and shoulder girdle, with occasional wavelike movements or contractions, especially in the trapezius. They showed increased galvanic irritability and anodal closing contraction equal to cathodal closing contraction. Especially in the outer part of the trapezius, the contraction was very slow to the galvanic current. The inner half of the same muscle gave normal galvanic response. There was no pain but a dull aching and sense of fatigue in the involved muscles.

I examined four patients for the myasthenic reaction. In two out of five examinations of the patient in Case 11 great weakness and atrophy of the muscles of the shoulders and back of the neck were found (Figs. 4 and 6 ).

SIGNS OF MENINGITIS

Sixteen of the twenty-five cases belonged to the "meningoradicular" type of the disease. Rigidity of the neck to a variable extent was present in twelve patients and in two mild opisthotonos. Dilatation of the pupils during the attempt to flex the neck was noticed in two of the patients. The Kernig sign was elicited in six patients, but it was not 
constantly present. A typical Babinski sign was noticed in two patients, an atypical Babinski in twelve. The Brudzinski collateral reflex, particularly his "neck sign," was observed in three patients.

\section{MISCELLANEOUS FINDINGS}

Enlargement of the spleen was always looked for but never found. Gastro-intestinal disturbance was not common, diarrhea was not observed. Gastric irritability was present in only two patients, both of whom showed evidence of vagus involvement. Obstinate constipation was present in four. Retention of urine was present in two patientsin one of four days' and in the other of six days' duration.

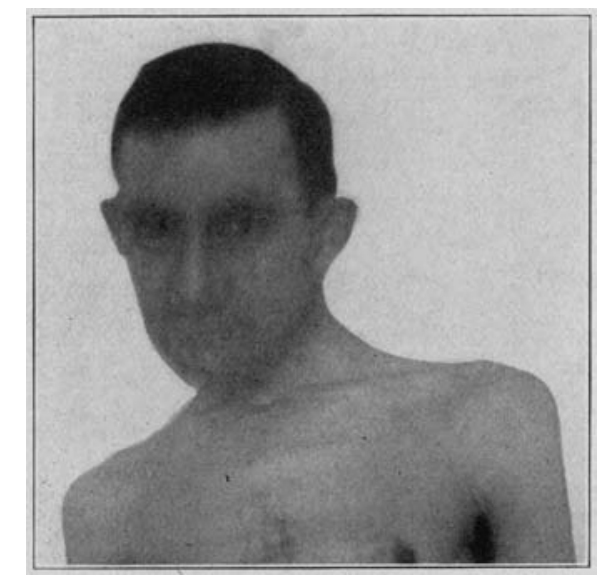

Fig. 6 (Case 11).-Paralysis of the muscles of the back of the neck. Weakness and atrophy of the muscles of the shoulder girdle are also present.

\section{LABORATORY FINDINGS}

Blood.-The red blood cells and hemoglobin showed no particular changes. If the disease was protracted, moderate secondary anemia developed. The details of the white biood counts and the differentials are tabulated in Table 1.

Chemical examination of the blood revealed nothing unusual but was an aid in differentiating the condition from other diseases in which nitrogen retention and hyperglycemia occur. As will be seen in Table 2, the blood sugar was normal in spite of the fact that in some of the cases glycosuria was present at the time.

\section{BACTERIOLOGIC FINDINGS}

The influenza bacillus of Pfeiffer was isolated from the throat in nine, and from the nose in six, out of twenty patients examined. A 
streptococcus was isolated from the throat twelve times and from the nose five times. Blood cultures were made in twenty cases with negative results.

The urine showed a slight trace of albumin in five cases. More than traces were not found, except in two fatal cases.

Table 1.-White and Differential. Blood Counts in Twenty-Five Cases of Epidemic Encephalitis

\begin{tabular}{|c|c|c|c|c|c|c|}
\hline $\begin{array}{l}\text { Case } \\
\text { No. }\end{array}$ & $\begin{array}{l}\text { White } \\
\text { Blood } \\
\text { Cells }\end{array}$ & $\begin{array}{l}\text { Poly- } \\
\text { morphonu- } \\
\text { clears }\end{array}$ & $\begin{array}{l}\text { Lympho- } \\
\text { cytes }\end{array}$ & $\begin{array}{l}\text { Mono- } \\
\text { nuelears } \\
\text { and Transi- } \\
\text { tionals }\end{array}$ & $\begin{array}{c}\text { Eosino- } \\
\text { phils }\end{array}$ & $\begin{array}{l}\text { Baso- } \\
\text { phils }\end{array}$ \\
\hline $\begin{array}{r}1 \\
2 \\
3 \\
4 \\
5 \\
6 \\
7 \\
8 \\
9 \\
10 \\
11 \\
12 \\
13 \\
14 \\
15 \\
16 \\
17 \\
18 \\
19 \\
20 \\
21 \\
22 \\
23 \\
24 \\
25\end{array}$ & $\begin{array}{r}6,400 \\
9,700 \\
6.200 \\
9.100 \\
7,400 \\
6,300 \\
8.100 \\
4,100 \\
10,300 \\
9,600 \\
8.800 \\
10,100 \\
9.000 \\
8,700 \\
6.600 \\
7,400 \\
6,600 \\
8,100 \\
9,100 \\
6,800 \\
7,400 \\
10,200 \\
11,800 \\
13,800 \\
6,500\end{array}$ & $\begin{array}{l}78 \\
73 \\
64 \\
72 \\
69 \\
76 \\
77 \\
60 \\
80 \\
74 \\
68 \\
72 \\
60 \\
84 \\
70 \\
74 \\
76 \\
64 \\
59 \\
77 \\
73 \\
84 \\
80 \\
67 \\
74\end{array}$ & $\begin{array}{l}14 \\
19 \\
25 \\
18 \\
22 \\
14 \\
14 \\
30 \\
15 \\
17 \\
23 \\
23 \\
30 \\
10 \\
18 \\
19 \\
16 \\
26 \\
36 \\
11 \\
13 \\
12 \\
11 \\
23 \\
15\end{array}$ & $\begin{array}{r}7 \\
4 \\
9 \\
8 \\
6 \\
7 \\
7 \\
5 \\
4 \\
7 \\
6 \\
\mathbf{4} \\
5 \\
5 \\
8 \\
\mathbf{5} \\
7 \\
8 \\
4 \\
9 \\
10 \\
\mathbf{3} \\
\mathbf{4} \\
7 \\
8\end{array}$ & $\begin{array}{l}1 \\
4 \\
2 \\
1 \\
3 \\
2 \\
2 \\
5 \\
1 \\
1 \\
3 \\
1 \\
5 \\
1 \\
4 \\
1 \\
1 \\
2 \\
0 \\
2 \\
4 \\
1 \\
5 \\
3 \\
3\end{array}$ & $\begin{array}{l}0 \\
0 \\
0 \\
1 \\
0 \\
1 \\
0 \\
0 \\
0 \\
1 \\
0 \\
2 \\
0 \\
0 \\
0 \\
1 \\
0 \\
0 \\
1 \\
1 \\
0 \\
0 \\
0 \\
0 \\
0\end{array}$ \\
\hline
\end{tabular}

Table 2.-Blood Chemistry Determinations in Sixteen Cases of Epidemic EnCEPhalitis *

\begin{tabular}{c|c|c|c}
\hline \hline Case No. & Blood Urea & Sugar & Creatinin \\
\hline 1 & 14 & 0.12 & 1.12 \\
2 & 12 & 0.07 & 1.0 \\
3 & 18 & 0.09 & 1.2 \\
4 & 10 & 0.11 & 0.9 \\
5 & 12 & 0.12 & 0.8 \\
6 & 10 & 0.07 & 1.2 \\
7 & 9 & 0.09 & 1.0 \\
8 & 8 & 0.08 & 0.9 \\
9 & 11 & 0.12 & 2.0 \\
10 & 10 & 0.13 & 1.1 \\
11 & 12 & 0.07 & 0.3 \\
12 & 14 & 0.09 & 0.91 \\
13 & 10 & 0.07 & 1.2 \\
14 & 8 & 0.08 & 1.2 \\
15 & 16 & 0.06 & 0.92 \\
\hline
\end{tabular}

* See also Table 4.

Sugar in the Urine.-A strikingly frequent finding was sugar in the urine. It was found at some period of the illness in nine cases. - The amount varied from 0.1 to 1.5 per cent. It was not present through the twenty-four hours, but no definite period, or relation to 
time of day or meals could be established. Sugar tolerance tests were made in four cases, and the determination of blood-sugar in sixteen cases.

There was no hyperglycemia in these cases, but all patients except those in Cases 9 and 15 had sugar in the urine at the time of the determinations. Four patients were given $100 \mathrm{gm}$. of dextrose, and blood sugar determinations were made at one-half hour intervals for three hours. In all, the sugar in the urine was increased, and there was also a considerable increase in the blood sugar which lasted for two and one-half or three hours.

Table 3.-Sugar Tolerance Test in a Case of Epidemic Enchphalitis

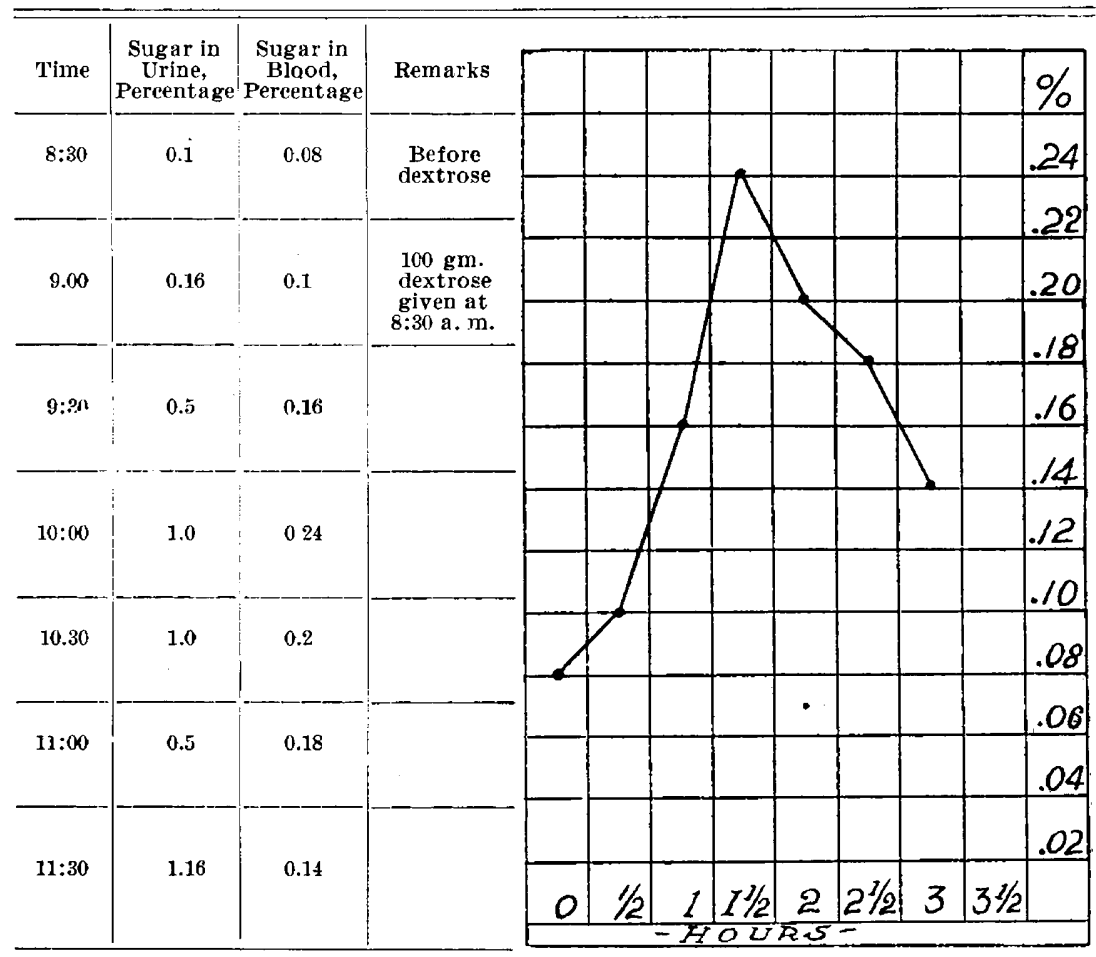

Other Elements in the Urine.-Nothing else abnormal, of any significance, was found. Acetone was present in two patients in both of whom it was associated with marked vomiting. Hyaline casts were present in the urine of the two patients whose urine had a moderate cloud of albumin.

\section{SPINAL FLUID}

The spinal fluid was clear in all cases. It was under moderately . increased pressure in seventeen of the twenty-one patients on whom 


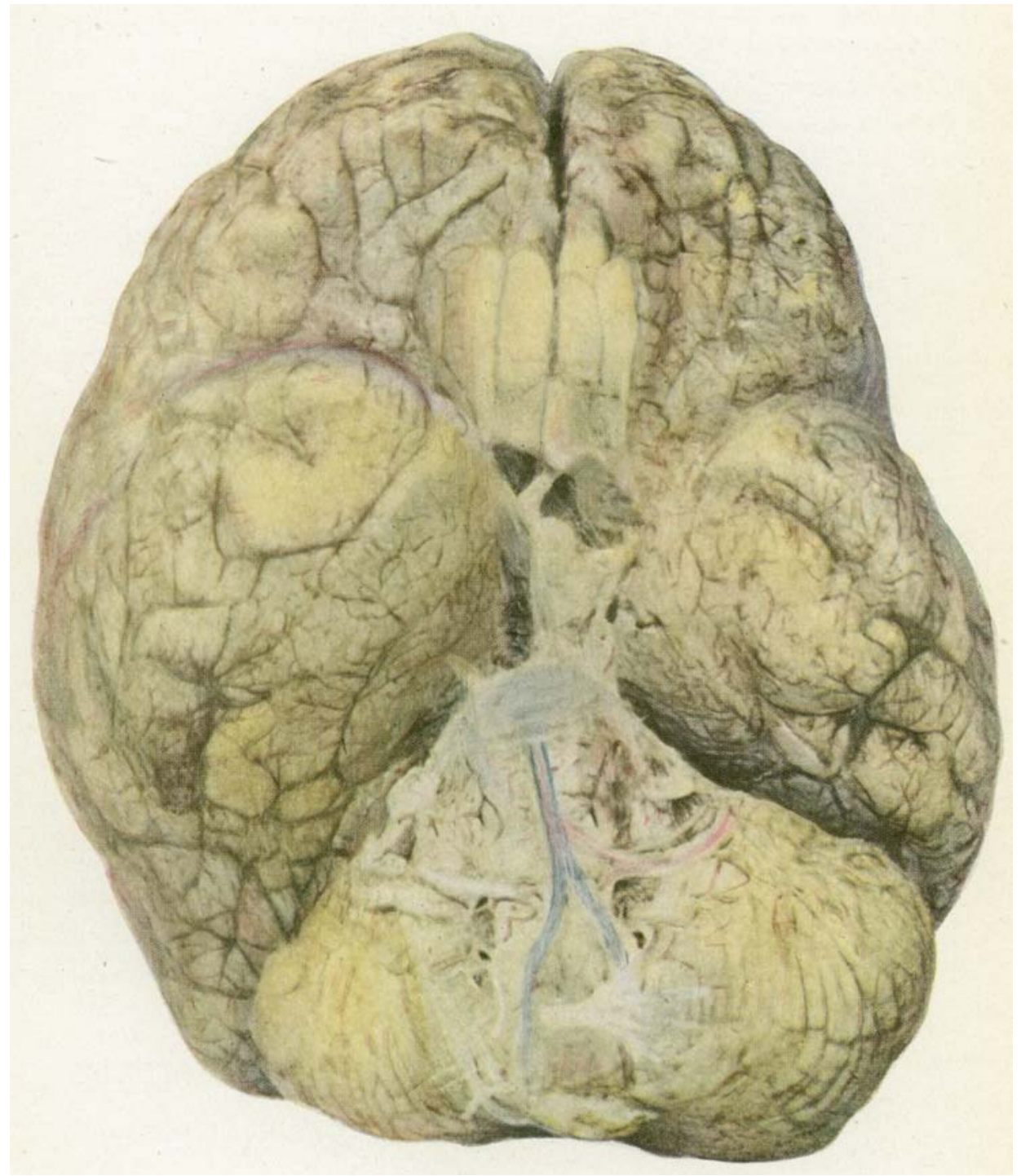

liig. 7 (Case 20). - Base of the brain showing marked hyperemia and a moderate exuclate, particularly in the region of the pons and medulla. 
lumbar puncture was performed. A trace of globulin was present in all cases, and in ten there was a marked precipitate. The cell count was below 10 in two cases. No organisms were found, and the Wassermann reaction was negative in all. Further details are given in Table 4.

\section{MISCELLANEOUS LABORATORY FINDINGS}

Chemical.-Microscopic and bacteriologic examination of the stools in twelve of the cases showed nothing unusual, and the same applies to gastric analysis made in four cases. The Widal test, performed in sixteen cases, showed no agglutination.

\section{GROSS AND MICROSCCPIC PATHOLOGY}

The pathologic findings were practically confined to the central nervous system. In one case definite granular degeneration and cloudy

Table 4.-The Findings in the Cerebrospinal Fluid in Twenty-One Cases of Epidemic Encephalitis

\begin{tabular}{|c|c|c|c|c|c|c|c|c|}
\hline $\begin{array}{c}\text { Case } \\
\text { No. }\end{array}$ & Cojor & $\begin{array}{c}\text { Fehling's } \\
\text { Redue- } \\
\text { tion }\end{array}$ & $\begin{array}{c}\text { Glob- } \\
\text { ulin }\end{array}$ & $\begin{array}{c}\text { Cell } \\
\text { Count }\end{array}$ & $\begin{array}{l}\text { Poly- } \\
\text { morpho- } \\
\text { nuclears }\end{array}$ & $\begin{array}{c}\text { Lympho- } \\
\text { cytes }\end{array}$ & Bacteria & $\begin{array}{c}\text { Wasser- } \\
\text { mann } \\
\text { Reaction }\end{array}$ \\
\hline $\begin{array}{r}1 \\
2 \\
3 \\
4 \\
5 \\
6 \\
7 \\
8 \\
9 \\
10 \\
11 \\
12 \\
13 \\
14 \\
15 \\
16 \\
17 \\
18 \\
19 \\
20 \\
21\end{array}$ & $\begin{array}{l}\text { Clear } \\
\text { Clear } \\
\text { Clear } \\
\text { Clear } \\
\text { Clear } \\
\text { Clear } \\
\text { Clear } \\
\text { Clear } \\
\text { Clear } \\
\text { Clear } \\
\text { Clear } \\
\text { Clear } \\
\text { Clear } \\
\text { Clear } \\
\text { Clear } \\
\text { Clear } \\
\text { Clear } \\
\text { Clear } \\
\text { Clear } \\
\text { Clear } \\
\text { Clear }\end{array}$ & $\begin{array}{c}\text { Normal } \\
\text { Normal } \\
\text { Normal } \\
\text { Normal } \\
\text { Normal } \\
\text { Normal } \\
\text { Normal } \\
\text { Diminished } \\
\text { Normal } \\
\text { Normal } \\
\text { Normal } \\
\text { Normal } \\
\text { Diminished } \\
\text { Normal } \\
\text { Normal } \\
\text { Normal } \\
\text { Normal } \\
\text { Normal } \\
\text { Normal } \\
\text { Normal } \\
\text { Diminished }\end{array}$ & $\begin{array}{c}++ \\
+++ \\
++ \\
+ \\
+ \\
++ \\
+ \\
+ \\
++ \\
++ \\
++ \\
+ \\
++ \\
++ \\
+ \\
+ \\
+ \\
+ \\
++ \\
++ \\
+\end{array}$ & $\begin{array}{r}27 \\
21 \\
30 \\
22 \\
14 \\
17 \\
9 \\
21 \\
25 \\
32 \\
41 \\
12 \\
26 \\
17 \\
9 \\
10 \\
14 \\
16 \\
17 \\
37 \\
22\end{array}$ & $\begin{array}{r}15 \\
7 \\
10 \\
13 \\
14 \\
10 \\
13 \\
12 \\
10 \\
9 \\
13 \\
7 \\
2 \\
5 \\
10 \\
7 \\
13 \\
14 \\
6 \\
11 \\
7\end{array}$ & $\begin{array}{l}85 \\
93 \\
90 \\
87 \\
86 \\
90 \\
87 \\
88 \\
90 \\
91 \\
87 \\
93 \\
98 \\
95 \\
90 \\
93 \\
87 \\
86 \\
94 \\
89 \\
93\end{array}$ & $\begin{array}{l}0 \\
0 \\
0 \\
0 \\
0 \\
0 \\
0 \\
0 \\
0 \\
0 \\
0 \\
0 \\
0 \\
0 \\
0 \\
0 \\
0 \\
0 \\
0 \\
0 \\
0\end{array}$ & $\begin{array}{l}0 \\
0 \\
0 \\
0 \\
0 \\
0 \\
0 \\
0 \\
0 \\
0 \\
0 \\
0 \\
0 \\
0 \\
0 \\
0 \\
0 \\
0 \\
0 \\
0 \\
0\end{array}$ \\
\hline
\end{tabular}

swelling were present in various organs, but the patient had a persistently high temperature which lasted for five days. The results of postmortem bacteriologic examination of the heart blood, various viscera, brain and meninges were negative.

We had occasion to examine two fetuses-both from spontaneous abortion. One was of eight months' gestation, the other of four and one half. In the older the meninges were normal, but the pia-arachnoid showed edema and congestion. There were microscopic hemorrhages in various parts of the brain and spinal cord, particularly at the base of the brain, and in the pons. Capillaries and veins were engorged and dilated, but there was no perivascular infiltration. There was also 
cellular degeneration, but no inflammatory changes. The whole was what one would expect in a fetus that has been dead in utero for some time. Findings in the younger fetus were similar.

In the adults the findings were the same as those described by other observers and by Allen and myself. ${ }^{1}$ These cases, it will be recalled, were characterized clinically by marked restlessness, choreiform jerking and peculiar twitchings of the abdominal muscles, and

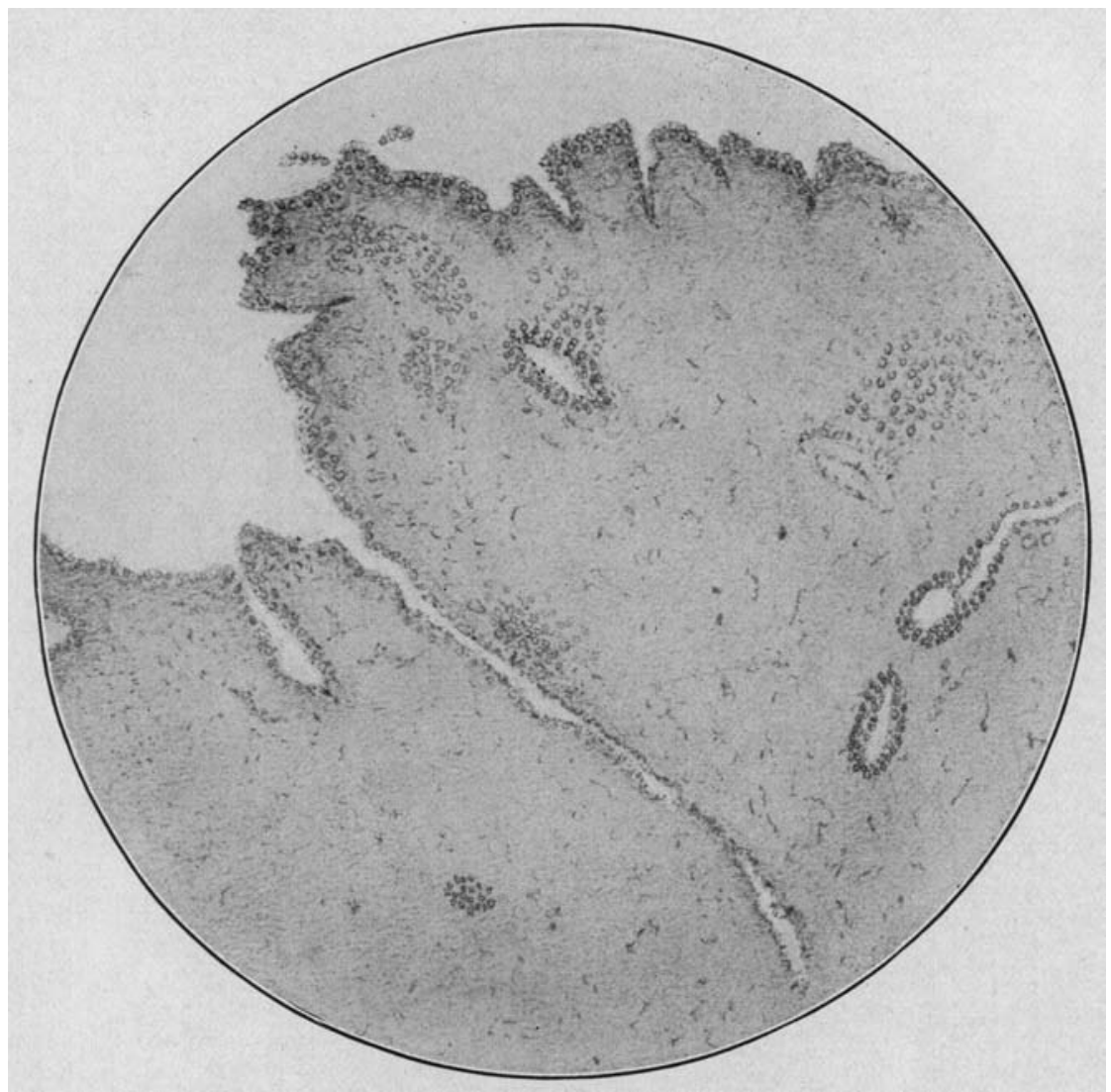

Fig. 8 (Case 20).-Base of the brain; round cell infiltration of the superficial layer; perivascular infiltration of the blood vessels.

were designated as the "meningoradicular" type. In addition to the usual findings in the brain substance, they showed pronounced changes in the meninges and spinal cord indicating that the disease was a meningo-encephalo-myelitis.

In two of our cases the meninges showed a marked degree of inflammation. The blood vessels were engorged and dilated, and there was a considerable amount of exudate at the base of the brain (Fig. 7). 


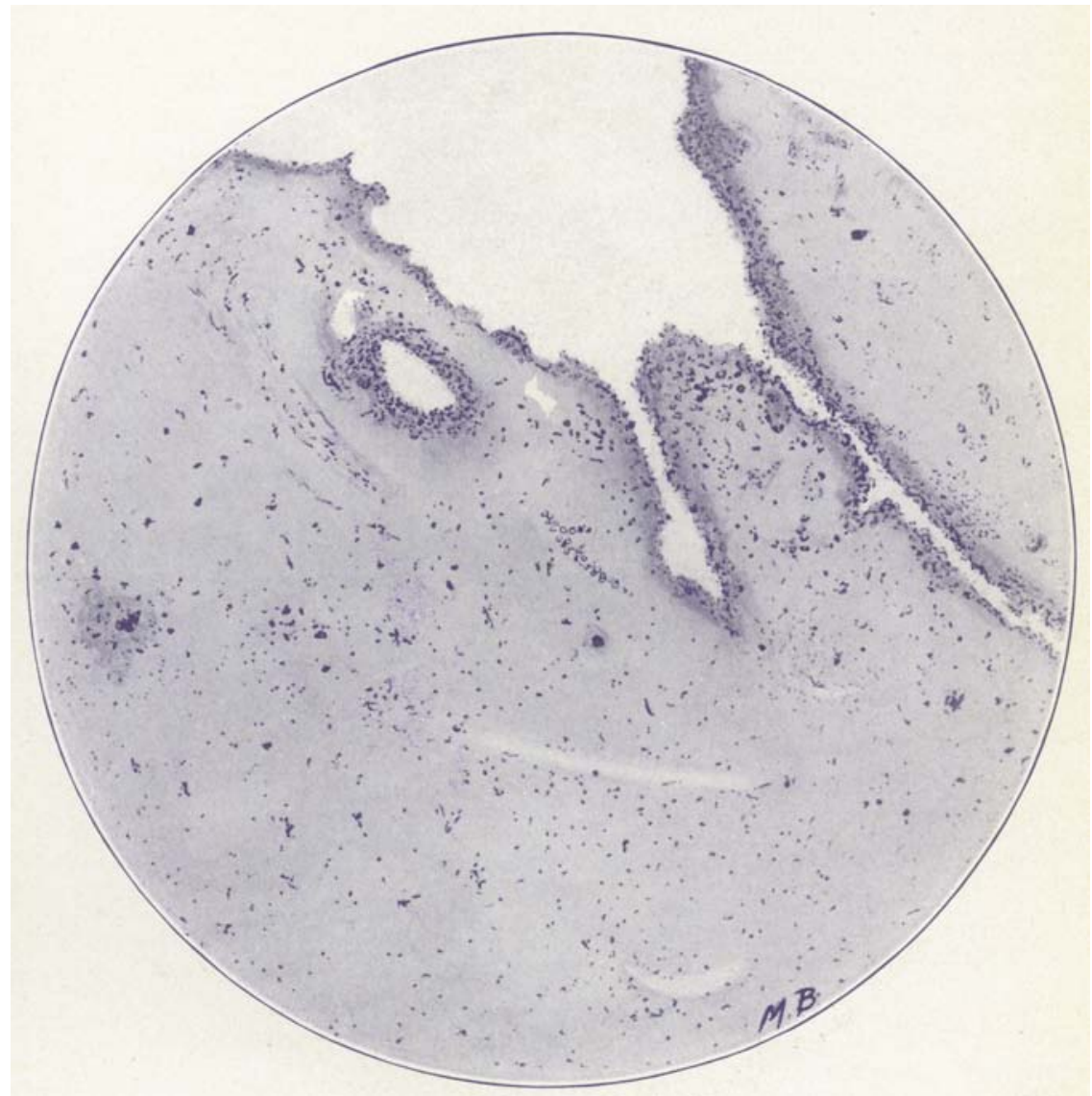

Fig. 9 (Case 24).-Base of the brain showing inflammatory involvement of the brain tissue just underneath the pia arachnoid. Note the diffuse cellular infiltration and the perivascular infiltration of the blood vessels. 
The pia was thickened and grayish-red. Smears and cultures from the exudate were invariably negative. On section tiny red spots were seen scattered throughout the brain substance but were most noticeable at the base, in the pons and the cerebral peduncles, where some of the spots were quite large, being from 2 to $3 \mathrm{~mm}$. in diameter. Minute hemorrhages were scattered throughout the cerebral cortex, basal ganglions, brain stem and spinal cord. The ventricles were slightly dilated and the ependyma thickened.

Microscopically the meninges showed marked inflammation, collections of inflammatory cells being found in divers parts. They were particularly frequent about the smaller blood vessels. Under high power these cells were found to be lymphocytes and mononuclears. Occasionally a polymorphonuclear leukocyte was seen in the adventitial lymph spaces.

The cortex showed slight dilatation of the capillaries and moderate cloudy swelling in some of the motor cells. The cells were swollen, the nuclei eccentric and there was some satellitosis.

At the base there was an unusual degree of inflammatory reaction just beneath the pia-arachnoid. In this region many accumulations of lymphoid cells were seen (Figs. 8 and 9). There was also diffuse infiltration with inflammatory cells. The vessels were dilated and showed marked perivascular infiltration with lymphocytes and mononuclears. The nerve cells in some places stained poorly, with some chromatolysis. In one case there was distinct inflammatory involvement of the olfactory bulb and optic nerve. The axis cylinders were swollen and stained freely and in some places were disintegrated. The protoplasm around the nuclei was increased in amount, and the nuclei were acentric. The blood vessels were congested and surrounded by mononuclear cells. In some places collections of lymphocytes and mononuclear cells were found at some distance from the blood vessels.

\section{CLASSIFICATION}

The twenty-five cases may be divided into five clinical types: (1) the lethargic type (one case), (2) the meningoradicular type (thirteen cases), (3) the paralysis agitans type (six cases), (4) the poliencephalitis type (two cases), and (5) the choreiform type (three cases).

The lethargic type was characterized by profound somnolence, cranial nerve palsies, especially of the third nerve, diplopia and masklike facies.

The meningoradicular type was marked by headache, cloudiness of sensorium, stiffness of the neck, pain along the course of the large nerves and by restlessness and twitching, often peculiar twitching of the abdominal muscles. A suggestive Kernig's sign and a pseudo or 
true Babinski sign were frequently seen. The spinal fluid generally had more pronounced increase of globulin and cells. Necropsy examination generally revealed more inflammation of the meninges and contiguous brain substance than in the other types.

The paralysis agitans type was characterized by a typical parkinsonian attitude and expression, various tremors and the characteristic position of the hand with "pill rolling" motion. The voice was monotonous and generally feeble. The gait was characteristic, and the patients sometimes volunteered the statement that they could run better than they could walk.

The poliencephalitis type was characterized by paralysis of one or more cranial nerves, most frequently the third and seventh. Lethargy and stupor were not prominent but marked asthenia was a feature. These cases suggested myasthenia gravis, and one patient gave a positive myasthenic reaction.

In the choreiform type the most pronounced disturbances were the extreme and persistent spasms. The patient blinked his eyes, jerked his head, twitched the mouth and made grotesque grimaces and contortions. One side of the body was generally more involved than the other. Cranial palsies were not prominent and were transient. The fever was generally quite high. Speech was thick and indistinct and deglutition difficult. The movements persisted even during sleep, although to a much less extent. Mild delirium was generally present at night but subsided toward morning.

\section{PROGNOSIS AND CONVALESCENCE}

Of the twenty-five cases in this series, four were fatal. Death apparently was due to involvement of the medullary centers. It was invariably preceded by marked disturbances in deglutition and respiration. Aggravation of the patient's condition frequently was rapid. Exceedingly few complications were seen.

Convalescence was generally slow. Exacerbations and remissions were frequent. The average duration of the disease in the mild cases was four weeks, of the moderately severe cases, about two months and of the severe cases, from three to five months. While progress is slow, it is constant. Two cases early in the epidemic were diagnosed as multiple sclerosis.

Of the twenty-one patients that survived, twelve are completely well. Five complain of lack of strength and endurance, nervousness, slight tremor and unsteadiness when excited or after moderate exertion, but they are doing some light work. The remainder are still more or less invalided - one fourteen months, and the other three, from nine to ten months after the onset of the illness. Their complaints are the same as those mentioned except to a more marked degree. Two of 
the patients also have cold and clammy hands and slight cyanosis of the finger tips. Three patients complain of excessive sweating and also have grooving of the nails. In two cases shedding of the nails took place.

The patients of the paralysis agitans type showed the slowest improvement. Nevertheless, of the six patients belonging to this group, all but two are well at the present time (nine to ten months after illness). Of the two, one is able to walk about and is doing a moderate amount of work. The second is still confined to bed during the greater part of the day, and after the slightest exertion exhibits generalized tremor and the characteristic position and tremor of the hands.

TREATMENT

Specific Treatment.-During the latter part of the epidemic I used convalescent serum in two cases. Twenty-five c.c. were injected intravenously, repeated in twenty-four hours. Both patients showed improvement soon after. The temperature came down to normal during the following three days and remained normal. The convalescence, however, did not seem to be shortened and the tremor, nervousness and twitchings persisted for six weeks in one case and for nine weeks in the other. The white blood count and the differential count showed no appreciable change following the injection of the serum.

General Treatment.-General care was relied on in the majority of cases. The most troublesome symptom in many cases was the dysphagia. It rendered feeding of the patient exceedingly difficult and also endangered life by the possibility of aspiration pneumonia or by suffocation. In three cases esophageal feedings were resorted to, in one case for three weeks. The patient made a complete recovery.

Sedatives.-Hypodermic injections of magnesium sulphate were tried for the twitchings and spasms but were of no benefit. Benzylbenzoate was also ineffective. Bromids and chloral were effective in large doses. Hypodermic injections of morphin and hyoscin were the most satisfactory and dram doses of paraldehyd were next in efficiency.

After the acute stage electricity and massage were of definite value.

SUM M ARY

The symptoms of the patients seen in the latter part of the epidemic varied greatly from those seen early. These symptoms were restlessness, twitching and insomnia, but the transition stages and the passing of the patients in a number of these restless and twitching cases into a state of lethargy with palsies of the cranial nerves show that they are cases of lethargic encephalitis. Laboratory and necropsy findings point to the same conclusion. 
While there was no relation between influenza and epidemic encephalitis in the individual cases, there was a suggestive relation between them in the community.

The symptomatology was extremely varied and resembled that of a great many neurologic diseases.

The pathologic findings consisted of minute hemorrhages in various parts of the nervous system with perivascular infltration of the capillaries and small blood vessels with round cells and lymphocytes. In the cases belonging to the meningoradicular type these changes were apt to be prominent and considerable involvement of the meninges and superficial brain tissues was frequently present. The blood frequently showed slight eosinophilia. Sugar was frequently present in the urine. There was no hyperglycemia, but the sugar tolerance was lowered.

The mortality in this series was 16.80 per cent. The patients that survived generally had a protracted convalescence, but all showed a definite and progressive improvement. 